\title{
ANÁLISE DE VIABILIDADE ECONÔMICA PERANTE TÉCNICAS CONSTRUTIVAS PARA UMA ESTRUTURA GEODÉSICA DE BAMBU
}

\section{ANALYSIS OF ECONOMIC VIABILITY BEFORE CONSTRUCTIVE TECHNIQUES FOR A GEODESIC STRUCTURE OF BAMBOO}

\section{Cinthia Mayara Geiss (Centro Universitário Leonardo da Vinci) Rafael Grosselli Damo (UNOESC)}

\author{
Palavras Chave \\ Bambu; Sustentabilidade; Geodésica
}

\section{Key Words}

Bamboo; Sustainability; Geodesic

\section{RESUMO}

Existe ainda um enorme preconceito para utilização do bambu, no Brasil, como material para a construção civil, fator este que se deve principalmente ao desconhecimento sobre as suas características em virtude à falta de normativa técnica. A sustentabilidade é primordial para o desenvolvimento mundial e o bambu atende as premissas para este conceito, podendo ser utilizado em diversas finalidades, entre elas a construção de leves estruturas flexíveis. Para a presente pesquisa foi elaborado um projeto de um centro artístico-cultural no interior do Município de Chapecó-SC, o volume projetado será um domo geodésica aonde o bambu tornou-se o protagonista da idealização, a partir de reflexões em bases teóricas foram determinadas duas técnicas construtivas diferenciadas, concluídas as propostas foram realizadas análises técnicas e econômicas para cada método executivo, em ambas as situações foram identificadas viabilidades nestas três etapas construtivas (fundações, tratamento e conexões), todavia segundo requerido pela proprietária do imóvel a ser realizada a execução do projeto, os quesitos econômicos e diminuição de impactos ambientais negativos foram mais relevantes no diagnóstico, em que uma das opções se mostrou mais viável nos parâmetros econômicos e o outro projeto no âmbito de viabilidade em sustentabilidade ambiental.

\section{ABSTRACT}

There is still enormous prejudice for the use of bamboo in Brazil as a material for civil construction, a factor that is mainly due to the lack of knowledge about its characteristics due to the lack of technical regulations. Sustainability is essential for global development and bamboo meets the requirements for this concept and can be used for various purposes, including the construction of lightweight flexible structures. For the present research was elaborated a project of an artistic-cultural center inside the Municipality of Chapecó-SC, the projected volume will be a geodesic dome where bamboo became the protagonist of the idealization, from reflections in theoretical bases were determined two Technical and economic analysis for each executive method, in both situations feasibility was identified in these three constructive stages (foundations, treatment and connections), however as required by the owner of the property to be carried out the execution of the Project, economic aspects and reduction of negative environmental impacts were more relevant in the diagnosis, in which one of the options was more feasible in the economic parameters and the other project in the scope of sustainability in environmental sustainability. 


\section{INTRODUÇÃO}

A definição de "Desenvolvimento Sustentável" foi consagrada, pelo Relatório de Brundtland, documento intitulado Nosso Futuro Comum, apresentado pela primeira- ministra da Noruega, (BRUNDTLAND, 1991) que consolida o termo como "um desenvolvimento que responda às necessidades do presente, sem comprometer a capacidade das gerações futuras de respondes às suas próprias necessidades".

Para Benavides (2012), o bambu é um material natural, concomitantemente sustentável, que reduz impactos ecológicos da construção no meio ambiente, por ser um material renovável e de fácil cultivo. Também, os bambuzais contribuem para o controle de erosão do solo, são fontes retentoras de água, ajudam a regular os cursos hídricos, possuem grande capacidade de retenção de $\mathrm{CO}^{2}$ e reduzem a temperatura do ambiente. Além disto, a energia de extração, transporte e matéria prima é praticamente nula em comparação com outros métodos construtivos, como a alvenaria convencional.

Por ser sustentável, o bambu traz consigo a dimensão ética e política de uma ferramenta capaz de gerar mudanças sociais através da autoconstrução, bem como equilíbrios ecológicos. Isto, porque é renovável, biodegradável e não gera custos de cultivo e manejo. Além disto, é de fácil execução, rápido crescimento da brotação até a fase adulta. No âmbito ambiental regula os recursos hídricos, auxilia na regeneração da mata nativa, contribui para o controle de erosão do solo e não motiva geração de energia na sua extração, ocasionalmente e opcionalmente gera alguma energia com transportes e seu processamento para utilização na construção civil.

O bambu como fonte de material estrutural é um componente excepcional, principalmente pela sua grande resistência à tração em relação a sua massa especifica, com valores superiores aos do aço. Além da sua leveza para o fácil manuseio e versatilidade na utilização, do mesmo modo possui excelentes características físicas para esta finalidade (PEREIRA, 2012).

As estruturas de bambu, para diversos fins, são confeccionadas há milênios, principalmente em regiões da Ásia e América. No Equador e na Colômbia essa cultura ainda é muito preservada, principalmente nas periferias das cidades e em zonas rurais, pelo seu baixo custo ou até mesmo pela proximidade dos bambuzais (BENAVIDES, 2012).

No Brasil, a utilização desta matéria prima ainda sofre preconceitos, principalmente pela falta de conhecimento sobre as técnicas construtivas, pois não há norma técnica regulamentada, e de forma pejorativa, segundo
Beraldo e Pereira (2008), o bambu é considerado a "madeira dos pobres" (mesmo não sendo uma madeira, pois biologicamente é caracterizado como uma gramínea), já nos países asiáticos, opostamente, o chamam de "ouro verde da floresta". Diante deste fato, e do pressuposto que a produção de pesquisa cientifica nesse âmbito, contribuirá para a disseminação de conhecimento técnico desta temática na esfera da construção civil, propôs realizar-se a presente pesquisa.

O objetivo principal é apresentar uma análise de viabilidade econômica de duas técnicas construtivas para uma estrutura geodésica de bambu, denominadas como: Domo Geodésico I e Domo Geodésico II. Os parâmetros para verificação e análise de informações, serão subdivididos por etapas executivas: fundação, tratamento e ligação entre os colmos (nós).

\section{METODOLOGIA}

\subsection{Projeto Arquitetônico}

Para o desenvolvimento desta pesquisa foi elaborado um projeto arquitetônico de um Domo Geodésico de bambu, destinado para um espaço de apresentações artístico-cultural, localizado em uma área rural denominada Linha Tafona, na cidade de Chapecó/SC.

O domo geodésico projetado possui área de $167,41 \mathrm{~m}^{2}$, com raio na base de 7,30m, aonde possui um palco central de $12,57 \mathrm{~m}^{2}$ e com quatro espaços adaptados aos portadores de necessidades especiais, a altura total do eixo da geodésica é de 5,04m. A área útil propicia uma previsão de até 50 expectadores sentados ao redor do palco central.

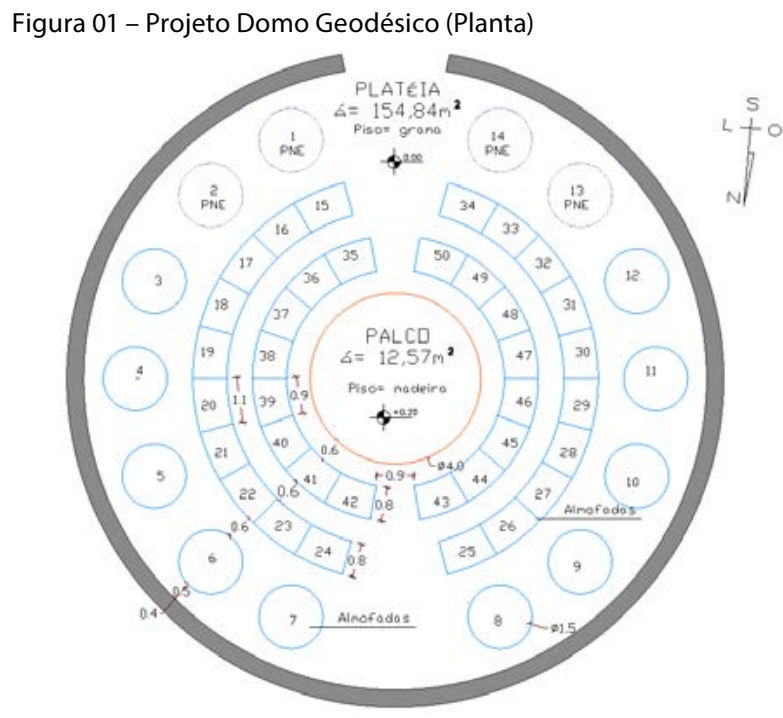

Fonte: Autor (2017) 
O conceito de uma estrutura geodésica, de acordo com (DINIZ, 2006) "é aquela trama composta por polígonos planos diversos onde a interseção das linhas retas destes polígonos, ou seus vértices, coincidem com uma superfície esférica ou oval" e conclui sua composição: nós, barras e sistema de cobertura (para estruturas fechadas).

\subsection{Técnica Construtiva}

A durabilidade do bambu está relacionada com a forma de tratamento preservativo de seu colmo, por ser um material biológico possui baixa durabilidade natural e alguns fatores contribuem para isto: o amido presente na parede interna do colmo atrai insetos que danificam o material, a umidade que contribui para sua degradação acelerada, bem como os microrganismos presentes no solo quando o bambu está em contato com este.

Para análise comparativa, optou-se por duas técnicas construtivas para fundações, dois métodos de tratamento dos colmos e dois procedimentos de conexões da estrutura, denominadas nesta pesquisa como "Domo Geodésico I" e "Domo Geodésico II", ambos descritos abaixo:

Figura 02 - Projeto Domo Geodésico (Vista Topo e Elevação)

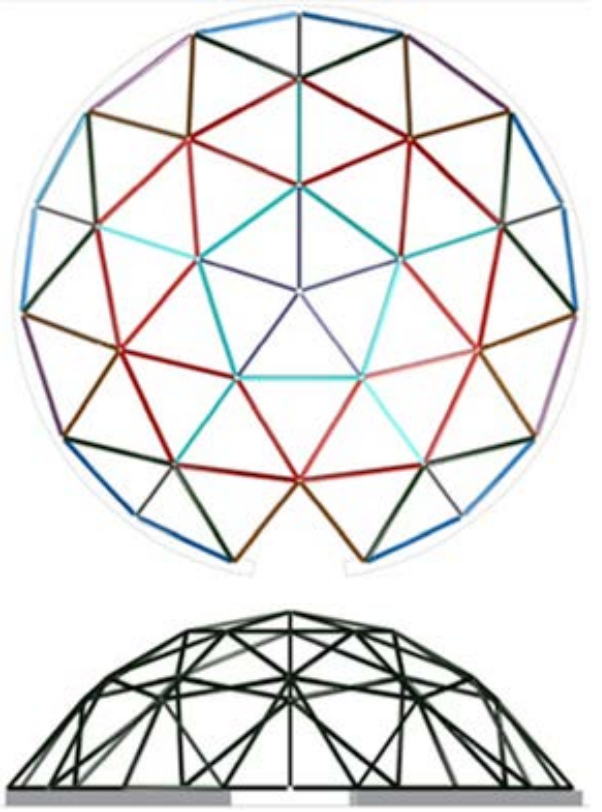

WFonte: Autor (2017)

\section{Domo Geodésico I}

Fundações: Alicerce no perímetro da base do domo geodésico com pedras de mão argamassadas, aonde serão aprofundados $30 \mathrm{~cm}$ e elevados $40 \mathrm{~cm}$ do nível do solo e a parede terá espessura de $40 \mathrm{~cm}$.

Vigas: O tratamento do bambu para esta opção será químico, da metodologia de imersão em solução hidrossolúvel, aonde os colmos devem permanecer de 8 a 10 dias imersos em uma solução de Ácido bórico, Bórax e Água na proporção 1:1:100, para isto escava-se uma vala e o solo é protegido por uma lona, para a solução não infiltrar e prejudicar o ambiente como para conter esta solução para que permaneça com a quantificação correta para tratar o bambu, após este procedimento deve-se retirar os colmos e armazená-los em local para secagem destes. A vedação nas extremidades será realizada com resina poliuretana a base de mamona e enxerto de serragem de bambu para preenchimento dos internós caso o corte não permita ser realizado logo após os nós mediante as dimensões exigidas.

Nós: As conexões serão feitas com tubos de PVC moldados e parafusados, a base da estrutura geodésica será fixada por abraçadeiras parafusadas no alicerce.

\section{Domo Geodésico II}

Fundações: Alicerce no perímetro da base do domo geodésico com tijolos maciços argamassados, aonde serão aprofundados $30 \mathrm{~cm}$ e elevados $40 \mathrm{~cm}$ do nível do solo e a parede terá espessura de $40 \mathrm{~cm}$.

Vigas: O tratamento optado será natural para os colmos, aplicando a técnica pela imersão em água, aonde os colmos após cortados serão amarrados por uma corda, formando um feixe e mergulhados em água corrente para liberação do amido presente no bambu, este processo será realizado em um pequeno rio que beira a propriedade e permanecerá lá de 3 a 4 semanas, após isto as varas serão armazenadas em local apropriado para secagem, livre de chuvas e sol. A vedação nas extremidades será realizada com resina poliuretana a base de mamona e enxerto de serragem de bambu para preenchimento dos internos, caso o corte das peças não permita ser realizado logo após os nós.

Nós: As conexões serão amarradas com corda natural de sisal, a fixação da base da estrutura geodésica terá abraçadeiras parafusadas no alicerce.

Figura 03 - Fundação Domo Geodésico I (Pedra Argamassada) e II (Tijolo maciço argamassado)

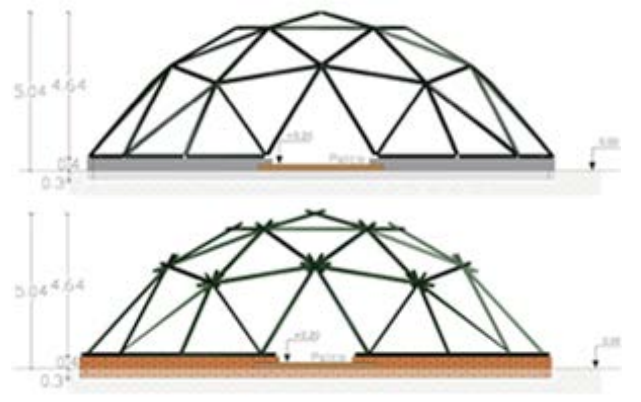

Fonte: Autor (2017) 


\subsection{Levantamento de Quantitativos e Custos}

As informações de quantidade de materiais a serem utilizados em cada um dos projetos desenvolvidos analisaram-se dimensões respectivas e especificações técnicas dos materiais a serem empregados. A metodologia bem como pesquisa na para composição de materiais e nomenclatura é baseada das instruções de Mattos (2006) e na TCPO - Tabela de Composição de Preços para Orçamentos (2010), ambas atuantes da Editora Pini e também em empresas da indústria da construção civil, além de pesquisa de referências técnicas como Beraldo e Pereira (2008) e Diniz (2006), os quais descrevem os métodos construtivos em bambu apresentados na pesquisa.

Para os custos de materiais dos dois projetos, foram realizadas pesquisas em empresas de construção civil, em sites de vendas on-line e nas tabelas de custos de insumos disponibilizadas pela Caixa Econômica Federal (2017), o qual gerou a composição materiais e valores descritos nas Tabelas 01 e 02:

Tabela 02: Orçamento de materiais para o projeto "Domo Geodésico I"

\begin{tabular}{|c|c|c|c|c|c|}
\hline ITEM & RELAÇÁO DE MATERIAIS & UND & QTDE & $\begin{array}{c}\text { VALOR } \\
\text { UNITÁRIO }\end{array}$ & $\begin{array}{l}\text { VALOR } \\
\text { TOTAL }\end{array}$ \\
\hline 1 & \multicolumn{5}{|l|}{ FUNDAÇÓES - Alicerces } \\
\hline 1.1 & Chapa compensada de Pinus, $\mathrm{e}=25 \mathrm{~mm}$ & $\mathrm{~m}^{2}$ & 36,06 & $\mathrm{R} \$ 53,83$ & $\mathrm{R} \$ 1.941,11$ \\
\hline 1.2 & Prego de aço polido $18 \times 27$ com cabeça & $\mathrm{kg}$ & 9,02 & $\mathrm{R} \$ 8,00$ & $\mathrm{R} \$ 72,16$ \\
\hline 1.3 & Areia tipo média (sem transporte) & $\mathrm{m}^{3}$ & 8,11 & $\mathrm{R} \$ 55,00$ & $\mathrm{R} \$ 446,05$ \\
\hline 1.4 & Pedra de máo (sem transporte) & $\mathrm{m}^{3}$ & 12,35 & $\mathrm{R} \$ 60,11$ & $\mathrm{R} \$ 742,53$ \\
\hline 1.5 & Cimento Portland CP II-32 & $\mathrm{kg}$ & 2444,90 & $\mathrm{R} \$ 0,52$ & $\mathrm{R} \$ 1.271,35$ \\
\hline \multicolumn{5}{|c|}{ TOTAL DAS FUNDAÇŌES } & $\mathrm{R} \$ 4.473,03$ \\
\hline 2 & VIGAS - Tratamento & & & & \\
\hline 2.1 & Varas de bambu Bambusa Tuldoide, $\varphi=6 \mathrm{~cm}$ & $\mathrm{~m}$ & 330,64 & $\mathrm{R} \$ 0,00$ & $\mathrm{R} \$ 0,00$ \\
\hline 2.2 & Lona plástica preta, 150 micras & $\mathrm{m}^{2}$ & 25 & $\mathrm{R} \$ 0,95$ & $\mathrm{R} \$ 23,75$ \\
\hline 2.3 & Ácido bórico & $\mathrm{kg}$ & 13 & $R \$ 4,80$ & $R \$ 62,40$ \\
\hline 2.4 & Bórax & $\mathrm{kg}$ & 13 & $R \$ 5,00$ & $\mathrm{R} \$ 65,00$ \\
\hline \multicolumn{5}{|c|}{ TOTAL DAS VIGAS } & $\mathrm{R} \$ 151,15$ \\
\hline 3 & CONEXÓES - Ligaçōes & & & & \\
\hline 3.1 & Verniz poliuretano vegetal Imperveg UG $132 \mathrm{~A}$ & $\mathrm{~kg}$ & 0,84 & $\mathrm{R} \$ 60,00$ & $R \$ 50,40$ \\
\hline 3.2 & Tubo de PVC marrom $\varphi 75 \mathrm{~mm}$, barra com $6 \mathrm{~m}$ & peça & 8 & $\mathrm{R} \$ 6,91$ & $R \$ 55,28$ \\
\hline 3.3 & Parafuso zincado, sextavado $5 / 16 " \times 110 \mathrm{~mm}$ & peça & 179 & $\mathrm{R} \$ 0,75$ & $\mathrm{R} \$ 134,25$ \\
\hline 3.4 & Porca zincada, sextavada $5 / 16 "$ & peça & 358 & $\mathrm{R} \$ 0,06$ & $R \$ 21,48$ \\
\hline 3.5 & Abraçadeira em, tipo U simples $3^{\prime \prime}$ & peça & 4 & $\mathrm{R} \$ \mathbf{1 , 2 1}$ & $\mathrm{R} \$ 4,84$ \\
\hline 3.6 & Parafuso de aço parabolt $3 / 8 " \times 75 \mathrm{~mm}$ & peça & 8 & R\$ 1,10 & $\mathrm{R} \$ 8,80$ \\
\hline \multicolumn{5}{|c|}{ TOTAL DAS CONEXŌES } & $\mathrm{R} \$ 275,05$ \\
\hline \multicolumn{5}{|c|}{ VALOR TOTAL FINAL } & $\mathrm{R} \$ 4.899,23$ \\
\hline
\end{tabular}

Tabela 02: Orçamento de materiais para o projeto "Domo Geodésico II"

\begin{tabular}{|c|c|c|c|c|c|}
\hline ITEM & RELAÇÃO DE MATERIAIS & UND & QTDE & $\begin{array}{c}\text { VALOR } \\
\text { UNITARIO }\end{array}$ & $\begin{array}{l}\text { VALOR } \\
\text { TOTAL }\end{array}$ \\
\hline 1 & \multicolumn{5}{|l|}{ FUNDAÇŌES - Alicerces } \\
\hline 1.1 & Tijolo maciço cerâmico $5,7 \times 9 \times 19 \mathrm{~cm}$, parede $40 \mathrm{~cm}$ & peça & 10202 & $\mathrm{R} \$ 0,82$ & $\mathrm{R} \$ 8.365,64$ \\
\hline 1.2 & Cimento Portland CP II-32 & $\mathrm{kg}$ & 700,63 & $\mathrm{R} \$ 0,52$ & $R \$ 364,33$ \\
\hline 1.3 & Cal hidratada CH I & $\mathrm{kg}$ & 700,63 & $\mathrm{R} \$ 0,47$ & $\mathrm{R} \$ 329,30$ \\
\hline \multirow[t]{2}{*}{1.4} & Areia tipo média (sem transporte) & $\mathrm{m}^{3}$ & 4,7 & $\mathrm{R} \$ 55,00$ & $\mathrm{R} \$ 258,50$ \\
\hline & \multicolumn{4}{|c|}{ TOTAL DAS FUNDAÇÖES } & $R \$ 9.317,76$ \\
\hline 2 & \multicolumn{5}{|l|}{ VIGAS - Tratamento } \\
\hline 2.1 & Varas de bambu Bambusa Tuldoide, $\varphi=6 \mathrm{~cm}$ & $\mathrm{~m}$ & 243,42 & $\mathrm{R} \$ 0,00$ & $\mathrm{R} \$ 0,00$ \\
\hline \multirow[t]{2}{*}{2.2} & Sisal em fibra $8 \mathrm{~mm}$ & $\mathrm{~kg}$ & 2,25 & $\mathrm{R} \$ 9,68$ & $\mathrm{R} \$ 21,78$ \\
\hline & \multicolumn{4}{|l|}{ TOTAL DAS VIGAS } & $R \$ 21,78$ \\
\hline 3 & \multicolumn{5}{|l|}{ CONEXŌES - Ligações } \\
\hline 3.1 & Verniz poliuretano vegetal /mperveg UG $132 \mathrm{~A}$ & $\mathrm{~kg}$ & 0,84 & $\mathrm{R} \$ 60,00$ & $\mathrm{R} \$ 50,40$ \\
\hline 3.2 & Sisal em fibra $8 \mathrm{~mm}$ & $\mathrm{~kg}$ & 3,5 & $R \$ 9,68$ & $\mathrm{R} \$ 33,88$ \\
\hline 3.3 & Abraçadeira em, tipo U simples 3" & peça & 4 & $\mathrm{R} \$ 1,21$ & $\mathrm{R} \$ 4,84$ \\
\hline \multirow[t]{2}{*}{3.4} & Parafuso de aço parabolt $3 / 8^{\prime \prime} \times 75 \mathrm{~mm}$ & peça & 8 & $\mathrm{R} \$ 1,10$ & $\mathrm{R} \$ 8,80$ \\
\hline & \multicolumn{4}{|c|}{ TOTAL DAS CONEXÖES } & $R \$ 97,92$ \\
\hline \multicolumn{5}{|c|}{ VALOR TOTAL FINAL } & $R \$ 9.437,46$ \\
\hline
\end{tabular}


É importante relatar a diferença de quantidade de cimento para as fundações entre os projetos, conforme itens da TCPO - Tabela de Composição de Preços para Orçamentos (2010), em que o cálculo total de cimento para ambos os casos dá-se por:

Para o "Domo Geodésico I", a fundação possui $12,47 \mathrm{~m}^{3}$ totais, os materiais foram adaptados do item 03310.8.3.1 (em que somente irá ser utilizada a pedra de mão, excluindo a pedra britada), são necessários $196 \mathrm{Kg}$ de cimento para cada $\mathrm{m}^{3}$ de alicerce, onde:

10) $12,47 \mathrm{~m}^{3}$ de alvenaria $\mathrm{X} 196 \mathrm{Kg}$ de cimento $=$ $2444,90 \mathrm{Kg}$ de cimento

No projeto do "Domo Geodésico II" foi constatada uma área total de fundação de $32,08 \mathrm{~m}^{2}$ com espessura de $0,40 \mathrm{~m}$, no item 04211.8 .1 .7 , consta que são necessários $0,06 \mathrm{~m}^{3}$ de argamassa para $\mathrm{m}^{2}$ de alvenaria com $19 \mathrm{~cm}$ de espessura e no item 04060.8.1.84 está descrito que são $182 \mathrm{Kg}$ de cimento para cada $\mathrm{m}^{3}$ de argamassa são precisos, então:

10) $32,08 \mathrm{~m}^{2}$ de alvenaria $X 0,06 \mathrm{~m}^{3}$ de argamassa $X 2$ espessuras de parede $=3,85 \mathrm{~m}^{3}$ de argamassa

$\left.2^{\circ}\right) 182 \mathrm{Kg}$ de cimento $\times 3,85 \mathrm{~m}^{3}$ de argamassa $=$ 700,63Kg de cimento

Os materiais dos itens 2.1 das tabelas 01 e 02 acima serão extraídos da propriedade em que a obra será executada e não haverá custos de insumos para estes, somente para o tratamento, como descrito nos quantitativos e orçamentos acima.

\section{RESULTADOS}

Com os dados obtidos através das Tabelas 01 e 02, pode-se obter uma análise de viabilidade econômica perante os métodos construtivos do "Domo Geodésico I" e o "Domo Geodésico II". Os parâmetros para verificação e análise de informações foram divididos por etapas de fundação, tratamento de vigas e conexão dos nós, o valor global da construção também será esclarecido, bem como uma relação de vantagens e desvantagens referente ao assunto abordado mediante análise sustentável e de técnicas construtivas seguem adiante.
Gráfico 01 - Custo das fundações "Domo Geodésico I" x "Domo Geodésico II"

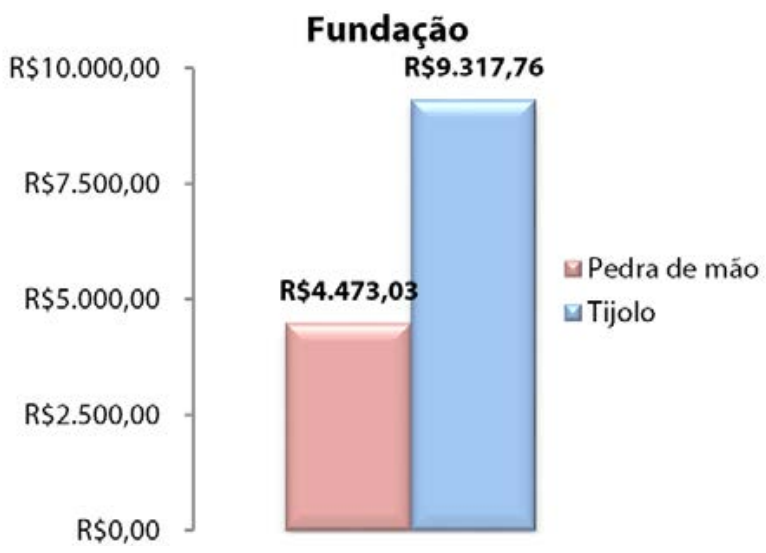

Fonte: Autor (2017)

De acordo com os valores expressos no Gráfico 01, observa-se que a construção do alicerce em tijolo maciço argamassado é $208,31 \%$ mais cara que o alicerce em pedra de mão argamassada. Os dois métodos poderão ser construídos pela própria cliente, conforme solicitado, sem contratação de mão de obra especializada, portanto há uma dificuldade maior em executar as formas de madeira para o Domo Geodésico I, devido ao formato circular do alicerce. Para os tijolos há uma geração de energia pelo calor necessário para fabricação do produto, porém há uma quantidade maior de argamassa no alicerce em pedra de mão, que também gera energia para confecção dos materiais, ambos necessitam de transporte até o local da obra, aonde ocorre a queima de combustível, com estas considerações ambas as soluções provocam impactos ambientais negativos.

Gráfico 02 - Custo do tratamento "Domo Geodésico I" x "Domo Geodésico II"

\section{Tratamentos}

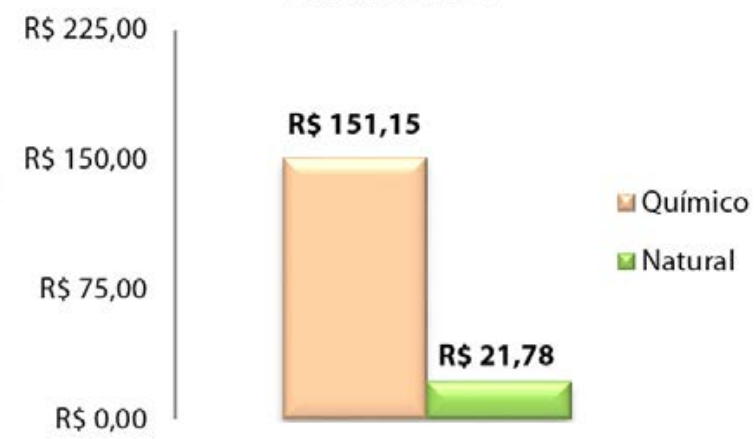

Fonte: Autor (2017)

O tratamento dos colmos de bambu, no quesito econômico é notoriamente diferenciado, o valor do método de imersão em solução hidrossolúvel é 693,99\% maior 
que imersão em água, porém conforme Pereira (2012), os tratamentos químicos, assim como nas madeiras, têm um resultado muito melhor, tanto em durabilidade quanto em eficiência. A técnica de imersão em água é mais prática para a autoconstrução, logo ambas são possíveis, porém a dificuldade maior no método do "Domo Geodésico I" é a escavação para vala aonde é feita a acomodação dos colmos que serão submersos na solução preservativa, além disto, a utilização de produtos químicos pode ser prejudicial ao meio ambiente, um cuidado maior ainda deve ocorrer com o descarte de maneira correta pelo processo de destinação a empresas especializadas no segmento ou diluído em grande quantidade de água (conforme entrevista com Stamm em anexo), para despejo em locais adequados para compostagem, à reutilização da composição também pode ser feita.

Gráfico 03 - Custo das conexões "Domo Geodésico I" x "Domo Geodésico II"

\section{Conexões}

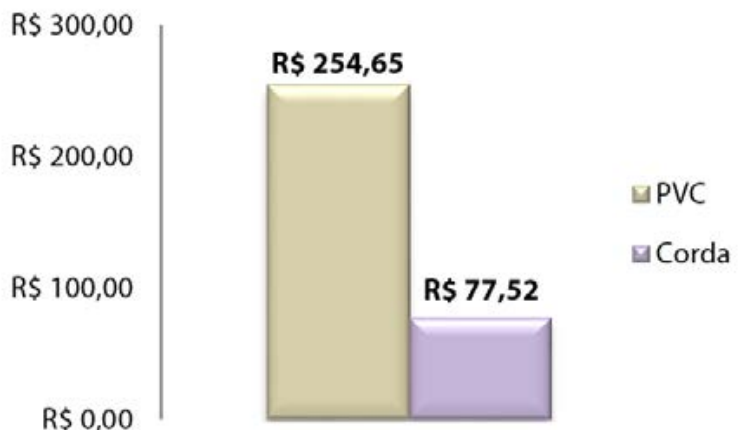

Fonte: Autor (2017)

As técnicas construtivas para as conexões também são possíveis de serem auto executadas, a estratégia aplicada no "Domo Geodésico I" é mais cara em relação ao "Domo Geodésico II" em 280,89\%, as dificuldades de execução avaliadas em comparação às duas metodologias são similares, na visão sustentável, a amarração tem uma viabilidade maior, por ser um material biodegradável, porém com exposição às intempéries degenera-se mais rapidamente que materiais poliméricos em geral, a corda de sisal proporciona maior atrito que cordas sintéticas na aderência aos colmos, o que favorece sua fixação. A vedação das extremidades dos colmos para evitar que um material higroscópico como o bambu seja prejudicado estruturalmente pelas patologias que pode apresentar se houver absorção de água pelas vigas, é igualmente aplicada em ambos projetos, sendo de fácil execução e baixo custo.

Gráfico 04 - Custo Global "Domo Geodésico I" x "Domo Geodésico II"

\section{Custo Global}

$$
\begin{aligned}
& \square \text { Domo } \\
& \text { Geodésico } \\
& \square \text { Domo } \\
& \text { Geodésico }
\end{aligned}
$$

$R \$ 4.899,23$

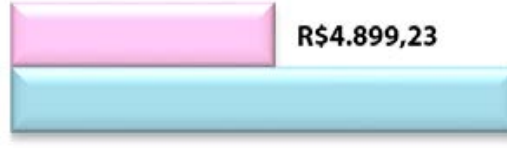

R\$9.437,46

$\mathrm{R} \$ 0,00$

$\mathrm{R} \$ 5.000,00$

$\mathrm{R} \$ 10.000,00$

Fonte: Autor (2017)

O custo global de cada projeto tem o quociente expresso no Gráfico 04 em que dadas informações pode-se analisar que o "Domo Geodésico II" torna-se economicamente mais oneroso, sendo $192,63 \%$ superior no valor global, porém mediante todas as técnicas construtivas empregadas fornece maior facilidade execução.

Gráfico 05: Custo por etapa "Domo Geodésico I" x "Domo Geodésico II"

Custo por Etapa

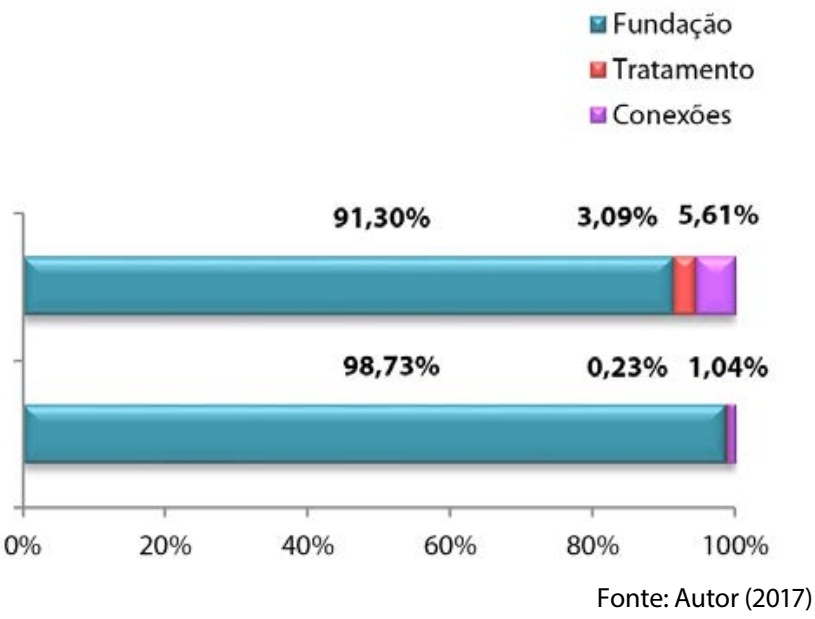

Em uma análise de custo de cada etapa construtiva (fundação, tratamento e conexões), constata-se que o maior valor empregado, assim como as maiores complexidades de execução e geração de impactos ambientais está nas fundações, que representam $91,30 \%$ no valor global do "Domo Geodésico I" e 98,73\% do “Domo Geodésico II", vistos do Gráfico 05, apesar do projeto do "Domo Geodésico I" possuir uma quantidade de cimento muito mais elevada.

Para poder viabilizar de uma maneira mais adequada é possível desenvolver outras técnicas construtivas e oportunizar o emprego de materiais locais, tal como minimizar o volume destes elementos. Uma pequena sapata 
elevada, somente nos locais de fixação da base da estrutura e com a utilização de seixos encontrados na propriedade, envoltos com argamassa possa ser uma alternativa para solucionar estes problemas.

O tratamento natural, segundo Beraldo e Pereira (2008), não possui uma eficácia tão prolongada quanto ao químico, o que pode prejudicar o resultado final da estrutura ao longo dos anos, porém os colmos podem ser substituídos facilmente conforme as necessidades e sem gerar custos adicionais à obra. De maneira geral as técnicas também provocam menores impactos ambientais no “Domo Geodésico II", pois nas vigas e nós os materiais são biodegradáveis, exceto na vedação das extremidades e no alicerce, aonde ambas as situações de projeto necessitam de uma destinação adequada em caso de inutilização dos materiais, mas de modo geral a maior viabilidade econômica é do projeto do "Domo Geodésico I".

Diante de todos os parâmetros descritos, há uma viabilidade economicamente superior no projeto "Domo Geodésico I" e tecnicamente no projeto "Domo Geodésico II", um simples relato de argumentações sobre as técnicas são expressos no seguinte quadro, mediante análise própria:

Quadro 01: Vantagens e Desvantagens "Domo Geodésico I" x "Domo Geodésico II"

\begin{tabular}{|c|c|c|c|c|}
\hline ETAPA & MÉTODO & VANTAGENS & DESVANTAGENS & OBSERVAÇŐES \\
\hline \multirow{2}{*}{ 岇 } & 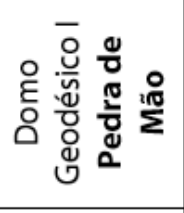 & $\begin{array}{l}\text { - Possibilidade de } \\
\text { autoconstruçáo }\end{array}$ & $\begin{array}{l}\text { - Grande impacto ambiental } \\
\text { - Necessita de transporte } \\
\text { - A execuçáo das formas agrega } \\
\text { uma dificuldade maior para } \\
\text { construçáo }\end{array}$ & \multirow{2}{*}{$\begin{array}{l}\text { Ambas possuem um } \\
\text { custo muito elevado } \\
\text { para a obra. }\end{array}$} \\
\hline & 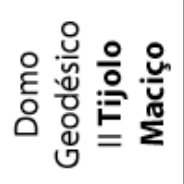 & $\begin{array}{l}\text { - Possibilidade de } \\
\text { autoconstruçáo }\end{array}$ & $\begin{array}{l}\text { - Grande impacto ambiental } \\
\text { - Necessita de transporte }\end{array}$ & \\
\hline \multirow{2}{*}{ 足 } & 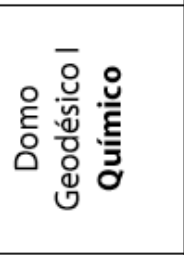 & $\begin{array}{l}\text { - Possibilidade de } \\
\text { autoconstruçáo } \\
\text { - Maior durabilidade } \\
\text { - Melhor eficiência } \\
\text { - Menor tempo de } \\
\text { execuçáo }\end{array}$ & $\begin{array}{l}\text { - Maior custo } \\
\text { - Impacto ambiental negativo } \\
\text { (necessita de descarte correto) }\end{array}$ & \multirow{2}{*}{$\begin{array}{l}\text { Náo há comprovaçóes } \\
\text { científicas ao tempo } \\
\text { preciso de durabilidade } \\
\text { de ambos. }\end{array}$} \\
\hline & 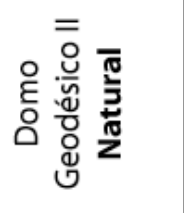 & $\begin{array}{l}\text {-Possibilidade de } \\
\text { autoconstruçáo } \\
\text { - Sem impactos } \\
\text { ambientais } \\
\text { - Menor custo }\end{array}$ & $\begin{array}{l}\text { - Menos eficiente } \\
\text { - Menor durabilidade } \\
\text { - Maior tempo de execuçáo }\end{array}$ & \\
\hline \multirow{2}{*}{ 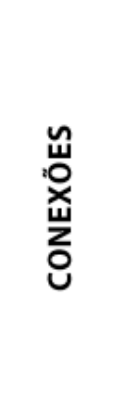 } & 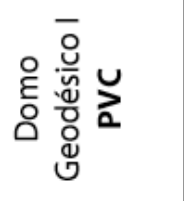 & $\begin{array}{l}\text { - Possibilidade de } \\
\text { autoconstruçáo } \\
\text { - Maior durabilidade } \\
\text { - Reaproveitado }\end{array}$ & $\begin{array}{l}\text { - Maior impacto ambiental para } \\
\text { produçáo dos materiais } \\
\text { - Maior custo }\end{array}$ & \multirow{2}{*}{$\begin{array}{l}\text { A estabilidade da } \\
\text { estrutura se dá pela } \\
\text { própria geometria, as } \\
\text { conexóes, se bem } \\
\text { executadas, sảo } \\
\text { eficientes igualmente. }\end{array}$} \\
\hline & 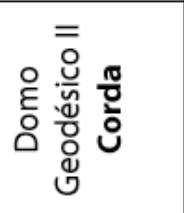 & $\begin{array}{l}\text { - Possibilidade de } \\
\text { autoconstruçáo } \\
\text { - Menor custo } \\
\text { - Sem impactos } \\
\text { ambientais }\end{array}$ & $\begin{array}{l}\text { - Degrada com maior rapidez } \\
\text { - Sem reutilizaçáo }\end{array}$ & \\
\hline
\end{tabular}

Fonte: Autor (2017)

\section{CONCLUSÕES}

Os resultados encontrados mostraram que o projeto do "Domo Geodésico II", no qual as técnicas empregadas foram: a construção de uma fundação de alicerce em tijolo maciço, tratamento natural das vigas com imersão em água corrente e a conexão dos nós amarradas com cordas de sisal, possui custo de $192,63 \%$ maior que o "Domo Geodésico I" em que a fundação projetada foi 
com alicerce de pedra de mão argamassada, tratamento químico das vigas pela metodologia hidrossolúvel e as conexões desenvolvidas por tubos de PVC parafusados. Porém no quesito sustentável, a conexão com cordas e o tratamento natural mostram-se mais eficazes.

A solução para atender as duas solicitações da proprietária, sustentabilidade e menor preço, pode-se elaborar um projeto com fundações de pedra de mão argamassada, tratamento natural e conexões amarradas com corda, aonde o valor total resultaria em $\mathrm{R} \$ 4.592,73$, resultado este inferior a ambos apresentados anteriormente. Dentre as melhorias há possibilidade de diminuir o volume das fundações, projetando somente pequenas peças isoladas localizadas nas bases de fixação da estrutura do domo geodésico de bambu. Porém como os itens de tratamento do bambu e conexão dos nós, nas duas situações, são valores praticamente desprezíveis em relação ao custo global da obra, indico o tratamento químico, pois diversos pesquisadores comentam sobre sua melhor eficiência em relação ao tratamento natural, além disto, também é possível fazer o descarte adequado do composto químico com diluição em água para compostagem e para as conexões indico em a técnica construtiva em PVC parafusado devido ao sisal ser um material degradável em contato com intempéries. Com estas instruções, tem-se a execução total do projeto "Domo Geodésico I".

Contudo, a utilização do bambu na construção civil é reconhecida por diversos pesquisadores no mundo, as inúmeras versatilidades e diversidades de aplicações deste material nas edificações o tornam um grande potencial da engenharia civil. Mediante suas características físicas, químicas e mecânicas, o bambu se transfigura em uma fonte alternativa de insumo, principalmente pelo fato da extinção de muitas madeiras e a da urgência sustentável que o mundo todo precisa buscar.

O propósito deste trabalho foi apresentar técnicas construtivas do bambu na construção civil com intuito de expandir informações relacionadas ao tema e o foco em orientações e averiguações técnicas/econômicas do emprego deste material em estruturas. Há ainda possibilidades de ampliar os conhecimentos sobre suas aplicações, baseando-se em normativas vigentes de outros países como Equador e Colômbia, podendo assim capacitar o aperfeiçoamento de projetos e execução de obras no Brasil. Pesquisas desenvolvidas com estes propósitos também contribuem para um maior aperfeiçoamento nos estudos de elaboração da Norma Técnica Brasileira que atualmente está em desenvolvimento.

\section{REFERÊNCIAS}

ASSOCIAÇÃO BRASILEIRA DE NORMAS TÉCNICAS. NBR 9050: Acessibilidade a edificações, mobiliário, espaços e equipamentos urbanos. 3 ed. Rio de Janeiro, 2015. 148 p.

ASSOCIAÇÃO BRASILEIRA DE NORMAS TÉCNICAS. NBR 13531: Elaboração de projetos de edificações - Atividades técnicas. Rio de Janeiro, 1995. 10 p.

BENAVIDES, A. S. J. Proposta de sistema construtivo para habitação de interesse social com bambu guadua: um estudo de caso no Equador. 2012. 144 f. Dissertação (Mestrado) - Curso de Arquitetura e Urbanismo, Universidade Federal de Santa Catarina, Florianópolis, 2012.

BerAldo, A. L.; PEREIRA, M. A. Bambu de Corpo e Alma. Bauru: Canal 6, 2008. 240 p.

BRUNDTLAND, G. H. Nosso Futuro Comum. 2. ed. Rio de Janeiro: FGV, 1991.

CAIXA ECONÔMICA FEDERAL. Relatório de Insumos e Composições - ABR/17 - COM DESONERAÇÃO. 2017. Disponível em: <http://www.caixa.gov.br/site/Paginas/ downloads.aspx\#categoria_662>.Acesso em: 13 maio 2017.

DETOIENTOIT. Une Coupole Geodesique en Bambou. 2008. Disponível em: <https://detoientoit.wordpress.com/2008/10/25/une-coupole-geodesique-en-bambou/>. Acesso em: 25 maio 2017.

DINIZ, J. A. V. Estruturas Geodésicas: Estudos retrospectivos e propostas para um espaço de educação ambiental. 2006. 143 f. Dissertação (Mestrado) - Curso de Engenharia Civil, Escola de Minas da Universidade Federal de Ouro Preto, Ouro Preto, 2006.

EDITORA PINI (Org.). TCPO: Tabela de Composição de Preços para Orçamentos. 13. ed. São Paulo: Pini, 2010. $630 \mathrm{p}$.

FULLER, R. B. SYNERGETICS: Explorations in the Geometry of Thinking. Sebastopol: Macmillan Publishing Co. Inc, 1975. 1839 p.

MATTOS, A. D. Como preparar orçamento de obras. São Paulo: Pini, 2006. 281 p. 
PADOVAN, R. B. O Bambu na Arquitetura: Design de Conexões Estruturais. 2010. 181 f. Dissertação (Mestrado) Curso de Arquitetura, Artes e Comunicação, Universidade Estadual Paulista "júlio de Mesquita Filho", Bauru, 2008.

PEREIRA, M. A. R. Projeto Bambu: Introdução de espécies, manejo, caracterização e aplicações. 2012. $100 \mathrm{f}$. Tese (Doutorado) - Curso de Design e Construção Com Bambu, Universidade Estadual Paulista "Julio de Mesquita Filho", Bauru, 2012.

QUINTERO, C. A. S. Desenvolvimento de uma Ligação estrutural para construção com bambu guadua. 2015. 117 f. Dissertação (Mestrado) - Curso de Arquitetura e Urbanismo, Universidade Federal de Santa Catarina, Florianópolis, 2015.

STAMM, J. La Evolución de los Métodos Constructivos en Bambú. In: SEGUNDO CONGRESSO MEXICANO DEL BAMBÚ, 1., 2008, Puebla. Estrategias Globales de Desarrollo Sustentable. Puebla: Congresso Mexicano del Bambú, 2008. p. 1 - 11.

VAN LENGEN, J. Manual do Arquiteto Descalço. São Paulo: B4, 2014. 736 p. 